Article

\title{
Feasibility of a Novel Industrial-Scale Treatment of Green Cold-Pressed Juices by UV-C Light Exposure
}

\author{
Michael Biancaniello ${ }^{1,2}$, Vladimir Popović ${ }^{2}$, Cristina Fernandez-Avila ${ }^{3}$, Valquiria Ros-Polski ${ }^{2}$ \\ and Tatiana Koutchma ${ }^{2, *}$ \\ 1 Department of Physics, University of Guelph, Guelph, ON N1G 2W1, Canada; mbiancan@uoguelph.ca \\ 2 Guelph Research and Development Center, Agriculture and Agri-Food Canada, Guelph, \\ ON N1G 5C9, Canada; vladimir.popovic@agr.gc.ca (V.P.); vrospolski@gmail.com (V.R.-P.) \\ 3 Department of Food Science, University of Guelph, Guelph, ON N1G 2W1, Canada; \\ cfernandezavila@gmail.com \\ * Correspondence: tatiana.koutchma@agr.gc.ca; Tel.: +1-(226)-217-8123
}

Academic Editors: Mohammed Mehdi Farid and Marliya Ismail

Received: 17 November 2017; Accepted: 20 March 2018; Published: 2 April 2018

\begin{abstract}
A novel industrial-scale ultraviolet-C (UV-C) light processor from AseptoRay (MGT, Israel) was used to treat a raw cold-pressed green juice blend (GJB) consisting of kale, romaine, celery, apple, and lemon. The effect of UV-C light energies of $0.88 \mathrm{~kJ} \mathrm{~L}^{-1}$ and $2.93 \mathrm{~kJ} \mathrm{~L}^{-1}$ on microbial, enzymatic, nutritional, quality, and sensory parameters of the GJB was studied. Using $2.93 \mathrm{~kJ} \mathrm{~L}^{-1}$, $3.7 \mathrm{log}$ reduction in aciduric bacteria and 3.9 logs in aerobic colony count were achieved, while lactic acid bacteria, coliforms, yeasts, and moulds were reduced by $>3,>2,2.1$, and 2.1 logs, respectively. A minor increase in polyphenoloxidase (PPO) enzyme activity was seen with $0.88 \mathrm{~kJ} \mathrm{~L}^{-1}$ and a slight change in colour (not visually observed) was detected using $2.93 \mathrm{~kJ} \mathrm{~L}^{-1}$. No other significant change in nutritional and quality parameters or enzyme activities was detected. Further, the stability of the GJB was explored. Kale and romaine contributed the most significant source of spoilage enzyme activity, cloud loss, and browning in the GJB. These stability parameters were shown to be affected by pressing temperature and $\mathrm{pH}$. The commercial UV-C treatment process explored in this study is a viable alternative to high pressure processing (HPP) for improved microbial safety of fresh green juice blends.
\end{abstract}

Keywords: UV-C; industrial; green juice blend; treatment; quality; nutrients; enzymes

\section{Introduction}

The cold-pressed premium juice industry has experienced fast growth around the world including Canada. The growing consumption of premium categories of juices has been attributed to the perceived health benefits of reduced calories, reduced sugar, and the "all natural", "made of organic ingredients" message based on high contents of enzymes, nutrients, and bioactive constituents. The addition of vegetable juices and fruit-vegetable blends also drives the low-calorie and health-beneficial messages. To achieve these attributes, the premium juice category is minimally processed using cold-pressing or other extraction methods to minimize treatment temperature and exposure to oxygen. Cold-pressing of juice is a two-stage process: first, grinding fruit or vegetables ingredients that were stored at refrigerated temperatures and then, extracting juice by gently pressing ingredients in special bags to prevent oxidation.

Initially, small point-of-sale local processors who produce juice and sell it fresh or unpasteurized with a shelf-life of a few days dominated the cold-pressed premium juice sector. The growth of the cold-pressed juice industry into regional and national markets requires higher juice yield after 
pressing, higher stability, safety and extension of product shelf-life to at least a few weeks. Thermal pasteurization is an effective preservation technique for extending shelf life of juices, but often negatively impacts both nutritional and quality parameters. An alternative processing strategy is the use of high-pressure processing (HPP). However, HPP is associated with high start-up and operational costs, batch processing while also requiring a large amount of space and use of plastic packaging [1].

Ultraviolet-C (UV-C) light is an alternative non-thermal treatment technology that has been approved by the U.S. FDA and Health Canada for the treatment of juice products [2,3]. Photochemical reactions and microbial inactivation proceed as a direct result of UV-C radiation energy (photons) absorbed by a food system. In order for the photochemical reaction to occur, the photons must first be absorbed by the molecules, and secondly, the photons must have enough energy to promote a reaction. The photochemical effect caused by UV-C light on bacteria and viruses is the formation of cyclobutane pyrimidine dimers in DNA and RNA, mainly thymine dimers. The structural damage caused by the formation of these dimers inhibits the formation of new DNA or RNA, resulting in the inactivation of the affected microorganism.

The regulatory approval of UV-C light emitted by low-pressure mercury lamps at $253.7 \mathrm{~nm}$ for treatment of juice products, opened new opportunities for the growing market of premium cold-pressed fruit and vegetable juices. UV-C light technology is a less expensive continuous process that is effective against all food borne pathogens, natural microbiota, moulds and yeasts, and extends shelf-life of juices such as popular leafy green products, fruit and vegetables, and nuts-based beverages while using various types of glass packaging. Currently, apple cider remains to be the only juice product for which a commercial UV-C process exists in Canada, meaning that only approved UV-C energy levels can be used by juice processors. However, there is a growing interest in manufacturing vegetable, leafy greens or nut based juices and beverages due to their health and low calories attributes.

Despite the existing regulatory approvals in the U.S. and Canada, the commercialization of UV-C light technology requires acceleration through research emphasis on the physical characteristics, quality, nutrient, enzymatic and microbial stability of juices and the changes in UV-C treated products. These data are critical for regulatory reviews of novel foods treated using UV-C technology, new product and process development, and juice storage stability.

In order to achieve high performance efficacy of UV-C light in products with low UV transmission (UVT) such as fresh non-clarified juices, new engineering approaches have been developed that differ from those normally employed for water treatment. Due to this challenge, UV-C systems use thin film laminar, annular turbulent or Dean flow in coiled tubes to treat low UVT fluids such as juice suspensions [4]. Based on the analysis of the reported data, Koutchma et al. (2016) concluded that low performance efficiency of lab/pilot-scale processing could lead to unnecessary over exposure by UV-C light and consequently result in lower quality product and formation of off-flavours [4].

The analysis of these results also indicated the importance of using the correct UV-C system and UV-C fluence measurement, control, and reporting. The main challenge for juice processors interested in using UV-C technology is in selecting the most appropriate UV-C light system and energy levels for their application and establishing optimal processing conditions, such that shelf-life objectives are achieved, while retaining the nutritional, sensory, and structure attributes of the product. However, very limited information has been reported in literature on the application of commercial scale UV-C systems, including CiderSure (Thin film laminar flow; FPE, NY, USA), Salcor module (Dean flow in coiled tube, turbulent; CA, USA) and SurePure (Thin film, turbulent; SurePure Inc., Zug, Switzerland). The effects of a commercial scale UV-C treatment at various energy levels on microbiological, quality, enzymatic, nutritional, and sensory parameters of juice products have not yet been reported. Also, there is very limited information on enzymatic activity of leafy fresh produce-popular ingredients used in green juices that can determine juice shelf-life and storage stability.

The main objective of this study was to test the feasibility of a novel UV-C commercial unit specifically developed for treatments of low UVT and opaque juices made by cold-pressing. The effect of UV-C light at 30\% and 100\% energy on natural microbiota, enzymatic activity, as well as quality, 
nutritional, and sensory attributes of a green juice blend (GJB) were measured. Additionally, the effect of $\mathrm{pH}$ and pressing temperature on the stability of juice made from fresh leafy green produce (kale and romaine) was explored.

\section{Materials and Methods}

\subsection{Materials}

Folin-Ciocalteu phenol reagent (2N), methylene blue, 2,6-dichlorophenolindophenol (DPIP), 2,2-diphenyl-1-picrylhydrazyl (DPPH), bromothymol blue, pectin (from citrus fruits), pyrocatechol, p-phenylenediamine, bovine serum albumin, 6-hydroxy-2,5,7,8-tetramethylchroman-2-carboxylic acid (Trolox), 2-7 dichlorofluorescein, gallic acid monohydrate, and 2,2'-azobis(2-amidinopropane) dihydrochloride (AAPH) were obtained from Sigma-Aldrich (St. Louise, MO, USA). L-ascorbic acid was purchased from Fisher Scientific (Ottawa, ON, Canada). Sodium dodecyl sulfate was purchased from Bio-Rad Laboratories (Saint-Laurent, QC, Canada). Orange serum agar, plate count agar (PCA), De Man, Rogosa and Sharpe (MRS) agar and potato dextrose agar (PDA) were obtained from Oxoid Limited (Hampshire, UK). 3M ${ }^{\mathrm{TM}}$ Petrifilm ${ }^{\mathrm{TM}}$ E. coli/Coliform Count Plates were purchased from 3M (Brockville, ON, Canada).

\subsection{GJB Preparation and Storage}

GJB from fresh kale, romaine, celery, and apple was produced by pressing the components together at room temperature in a manually operated industrial hydraulic cold press for approximately $10 \mathrm{~s}$ (Goodnature X-6; Orchard Park, NY, USA). Freshly squeezed lemon juice was added to the GJB for acidification purposes. The final composition of the GJB was $12.54 \%$ romaine, $25.07 \%$ celery, $12.54 \%$ kale, $37.32 \%$ apple, and $12.54 \%$ lemon by weight. The individual juices themselves were also collected for enzyme testing. Pressed GJB was kept at $4{ }^{\circ} \mathrm{C}$ in a refrigerator overnight before UV-C treatment and was stirred thoroughly before each trial to ensure homogeneity. A single batch of the GJB was used for the untreated and treated samples. Post-treatment, samples were stored in a dark cooler filled with ice until transported to the laboratory. All samples were transferred into $50 \mathrm{~mL}$ conical tubes and stored at $-20{ }^{\circ} \mathrm{C}$ for up to six weeks. Frozen juice samples were thawed immediately prior to testing.

\subsection{Kale and Romaine Juice Preparation and Storage for Pressing Temperature and $p H$ Studies}

Approximately $1.3 \mathrm{~kg}$ of fresh kale and romaine was stored at $4{ }^{\circ} \mathrm{C}$ and cold-pressed using a benchtop hydraulic press (Goodnature Countertop CT7; Orchard Park, NY, USA) at both room temperature and at $4{ }^{\circ} \mathrm{C}$. These samples were obtained from the same source as those used for commercial pressing of the GJB and were used to test the effect of temperature on spoilage enzyme activity as well as the effect of $\mathrm{pH}$ on browning and cloud loss. The kale and romaine were first shredded at $2500 \mathrm{rpm}$ (Robot Coupe Blixer 6V; Ridgeland, MS, USA) for $25 \mathrm{~s}$ and $15 \mathrm{~s}$, respectively. The shredded produce was then placed in a coarse disposable filter bag ( 275 microns) and pressed at "slow" speed to recover juice. Pressed juice was then transferred into $50 \mathrm{~mL}$ conical tubes and stored at $-20{ }^{\circ} \mathrm{C}$. Frozen juice samples were thawed immediately prior to testing.

\subsection{Commercial UV-C Unit and Treatment Parameters}

AseptoRay commercial UV-C unit (MGT industries Ltd., Ma'alot-Tarshiha, Israel) consists of the following major modules: skid (1); power and control board (2); product pump (3); balance tank (4); flow meter (5); UV-C lamps chamber and product tube (6), process control sensors and valves (7-9) (Figure 1a). 


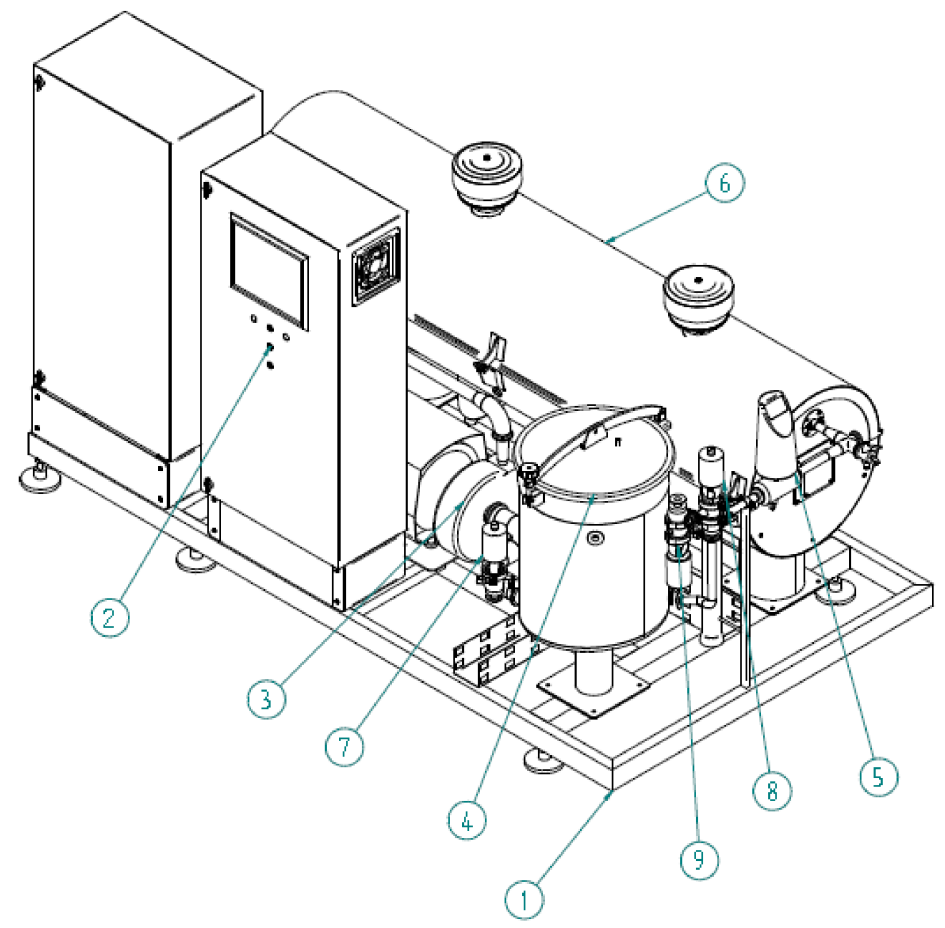

(a)

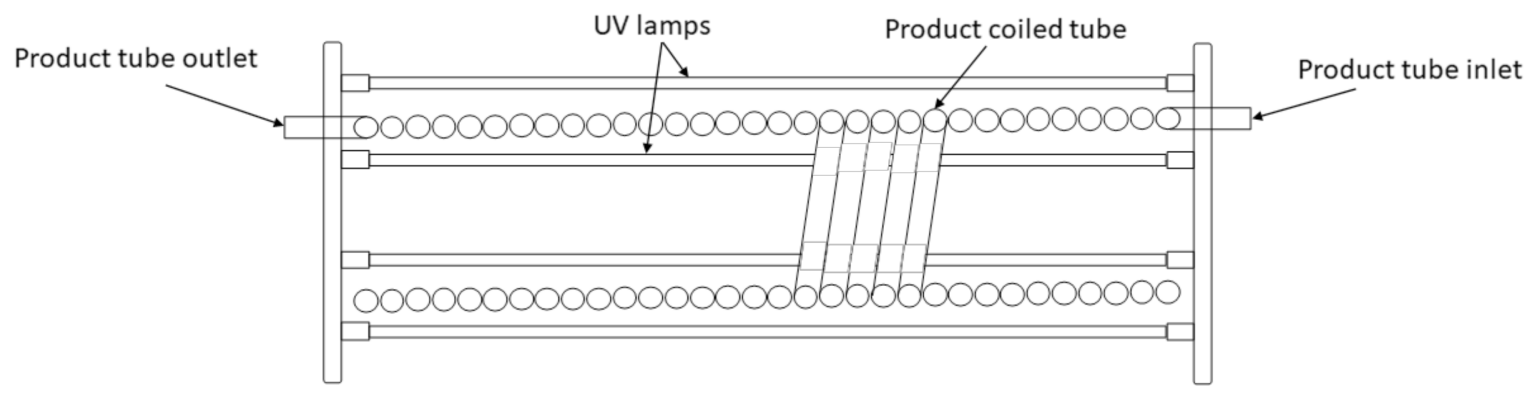

(b)

Figure 1. (a) Schematic drawing of the AseptoRay commercial ultraviolet-C (UV-C) processing unit. Skid (1); power and control board (2); product pump (3); balance tank (4); flow meter (5); UV-C lamps chamber and product tube (6); process control sensors and valves (7-9); (b) UV-C lamp chamber with coil tube and lamps.

The UV-C chamber of the unit shown in Figure $1 \mathrm{~b}$ contains UV-C transparent plastic tubing that is surrounded by low-pressure amalgam UV-C lamps. The commercial UV-C unit delivers light photons to the entire sample volume when it is pumped in turbulent flow through the tubing, creating Dean vortexes and enabling the UV-C light to interact with the liquid. The use of plastic tubing in food processing facilities ensures that safety and HACCP requirements are met by eliminating the hazards associated with the use of glass. The UV-C fluence level can be adjusted for each individual product based on their characteristics and microbial reduction requirements. Two treatment levels at 30\% and $100 \%$ energy were tested in the study. Two temperature sensors control air and product temperatures in the UV-C chamber, whereas two UV-C sensors monitor the incident intensity of UV-C light that is delivered to the treated product. The technical specifications of the UV-C lamps and flow parameters are presented in Table 1. Reynolds number (Re) was calculated for water and the GJB indicating a turbulent flow regime of juice treatment. 
Table 1. Lamp and flow parameters of the commercial UV-C unit.

\begin{tabular}{cc}
\hline \multicolumn{2}{c}{ UV-C Lamp Parameters } \\
\hline UV-C lamp intensity $\left(\mu \mathrm{W} \mathrm{cm}{ }^{-2}\right)$ & 750 \\
Total UV lamp output, $P_{\mathrm{UV}-\mathrm{C}}(\mathrm{W})$ & 320 \\
UV-C lamp output at $253.7 \mathrm{~nm}, P_{\mathrm{UV}-\mathrm{C}}(\mathrm{W})$ & 105 \\
UV-C lamp efficiency $(\%)$ & 32.8 \\
\hline \multicolumn{2}{c}{ Flow Parameters } \\
\hline Flow rate, $Q,\left(\mathrm{~L} \mathrm{~h}^{-1}\right)$ & 1000 \\
Flow rate $\left(\mathrm{m}^{3} \mathrm{~s}^{-1}\right)$ & 0.00028 \\
Residence time $(\mathrm{s})$ & 27 \\
Reynolds number $($ water $)$ & 35,769 \\
Reynolds number $(\mathrm{GJB})$ & 19,894 \\
\hline
\end{tabular}

\subsection{UV-C Processing Parameters}

UV-C treatment of $40 \mathrm{~L}$ of GJB product was performed at the average flow rate of $980-1000 \mathrm{~L} \mathrm{~h}^{-1}$ using either $30 \%\left(0.88 \mathrm{~kJ} \mathrm{~L}^{-1}\right)$ or $100 \%\left(2.93 \mathrm{~kJ} \mathrm{~L}^{-1}\right)$ of the unit's total UV-C energy. The $30 \%$ level of UV-C energy was selected based on the energy approved by Health Canada for apple juice and cider treatment. At 30\% UV-C energy, the lamps remained uniformly distributed around the tube with the product.

The total applied UV and UV-C energy $\left(E_{\mathrm{UV}}, \mathrm{J} \mathrm{L}^{-1}\right)$ (Equation (1)) was evaluated based on the number of UV-C sources $(N)$ turned-on with single source power $\left(P_{\mathrm{UV}}\right)$ and volumetric flow rate of treated juice $(Q)$ (Table 3$)$.

$$
E_{\mathrm{UV}}=\left(P_{\mathrm{UV}} \times N\right) / Q
$$

The total output power in the UV-C range $\left(\mathrm{P}_{\mathrm{UV}-\mathrm{C}}\right)$ is $32.8 \%$ (Table 1 ) of the total wattage for low-pressure mercury and amalgam lamps. Also, the UV transparency of the plastic tubing was taken into account in the calculations. The incident and absorbed UV-C fluence of treated juice was estimated based on the difference in the fluence rate readings of the internal UV-C sensors for water and juice multiplied by residence time using a proprietary algorithm and tube geometry (Table 2).

Table 2. UV-C treatment parameters of the commercial UV-C unit at 30\% and $100 \%$ energy.

\begin{tabular}{ccc}
\hline Commercial UV-C Unit & $\mathbf{3 0} \%$ & $\mathbf{1 0 0 \%}$ \\
\hline Number of lamps & 6 & 20 \\
Total input power $(\mathrm{W})$ & 1920 & 6400 \\
Tube UV transparency $(1=100 \% \ldots=0 \%)$ & 0.4 & 0.4 \\
UV-C factor $(\%)$ & 32.8 & 32.8 \\
Total UV-C output $(\mathrm{W})$ & 246 & 819 \\
Total input energy per volume $\left(\mathrm{J} \mathrm{m}^{-3}\right)$ & $2,742,857$ & $9,142,857$ \\
UV-C energy per volume $\left(\mathrm{J} \mathrm{m}^{-3}\right)$ & 877,714 & $2,925,714$ \\
UV-C energy input per pass $\left(\mathrm{kJ} \mathrm{L}^{-1}\right)$ & 0.88 & 2.93 \\
Incident UV-C fluence $\left(\mathrm{mJ} \mathrm{cm}^{-2}\right)$ & 53.3 & 411.4 \\
* Absorbed fluence per pass $\left(\mathrm{mJ} \mathrm{cm}^{-2}\right)$ & 18.9 & 61.3
\end{tabular}

* Data is based on the readings of UV sensors and calculations using a proprietary algorithm based on the tube geometry and UVT.

Tap water was circulated through the unit during the lamp warm-up period and prior to sample treatment. Treatment parameters such as pressure and initial and final product temperature were measured and summarized in Table 3. 
Table 3. Treatment parameters of the commercial UV-C unit at $30 \%$ and $100 \%$ energy.

\begin{tabular}{ccc}
\hline Parameters & $\mathbf{3 0 \%}$ & $\mathbf{1 0 0 \%}$ \\
\hline UV-C energy input $\left(\mathrm{kJ} \mathrm{L}^{-1}\right)$ & 0.88 & 2.93 \\
Flow rate $\left(\mathrm{L} \mathrm{h}^{-1}\right)$ & 996 & 983 \\
Pressure $(\mathrm{Bar})$ & 7.29 & 7.13 \\
Internal reactor temperature $\left({ }^{\circ} \mathrm{C}\right)$ & 46 & 99 \\
Conductivity $\left(\mu \mathrm{S} \mathrm{cm}{ }^{-1}\right)$ & 6151 & 6151 \\
Number of passes & 1 & 1 \\
Raw product temperature $\left({ }^{\circ} \mathrm{C}\right)$ & 5 & 7 \\
Final product temperature $\left({ }^{\circ} \mathrm{C}\right)$ & 13 & 17 \\
$\Delta T\left({ }^{\circ} \mathrm{C}\right)$ & 8 & 10 \\
\hline
\end{tabular}

\subsection{Microbiological Evaluation}

Microbiological counts of the untreated and treated GJB at 30\% and 100\% UV-C energy were assessed using an external certified laboratory. Three $250 \mathrm{~mL}$ juice aliquots were collected directly after processing and kept refrigerated at $4{ }^{\circ} \mathrm{C}$ for a maximum of $3 \mathrm{~h}$ before each determination. Experiments were conducted in triplicate and the detection limit of the tests was $10 \mathrm{CFU} / \mathrm{g}$. Aciduric bacteria were enumerated on orange serum agar incubated at $30^{\circ} \mathrm{C}$ for $48 \mathrm{~h}$. Aerobic colony count (ACC) was determined using PCA incubated at $30^{\circ} \mathrm{C}$ for $48 \mathrm{~h}$. Lactic acid bacteria (LAB) were enumerated on MRS agar and incubated at $35^{\circ} \mathrm{C}$ for $48 \mathrm{~h}$. Yeasts and moulds were enumerated on PDA medium and incubated at $22^{\circ} \mathrm{C}$ for 5 days. Coliforms and E. coli counts were determined in $3 \mathrm{M}^{\mathrm{TM}}$ Petrifilm ${ }^{\mathrm{TM}}$ E. coli/Coliform Count Plates, and incubated at $35^{\circ} \mathrm{C}$ for $24 \mathrm{~h}$. Results were expressed as the log of the number of colony forming units (CFU) per gram of sample and as the specific logarithmic reduction (SLR) of CFU per gram of sample calculated as a difference between logs of microbial counts before UV-C treatment $\left(N_{\mathrm{o}}\right)$ and after treatment at $30 \%$ and $100 \%$ UV-C energy $(N)$.

$$
\operatorname{SLR}=\log _{10}\left(N_{\mathrm{o}}\right)-\log _{10}(N)
$$

Untreated and treated sample data for the 30\% UV-C energy level was reported to a single significant digit.

\subsection{Quality Parameters}

2.7.1. Determination of Total Soluble Solids, $\mathrm{pH}$, Viscosity, Titratable Acidity, and Absorption Coefficient

Total soluble solids were determined at room temperature using a hand-held refractometer (R-5000, ATAGO Co., Ltd., Tokyo, Japan). The $\mathrm{pH}$ of the juice was measured with a benchtop pH meter (Orion 3-Star, Thermo Scientific, Waltham, MA, USA). Viscosity was determined using a viscometer with a small sample adapter (Brookfield DV-II+ Pro, AMETEK Brookfield, Middleboro, MA, USA). Titratable acidity was determined based on the official method outlined by AOAC (1995) [5]. In short, $5 \mathrm{~mL}$ of juice was diluted in $15 \mathrm{~mL}$ distilled water and titrated against a standard $0.1 \mathrm{M} \mathrm{NaOH}$ solution to a phenolphthalein end point $(\mathrm{pH} 8.2 \pm 0.1)$. The titratable acidity was calculated using the equation:

$$
\mathrm{TA}(\%)=\frac{V * 0.1 \mathrm{~N} \mathrm{NaOH} * 0.067 * 100}{m},
$$

where $V$ is the volume of $\mathrm{NaOH}$ used in $\mathrm{mL}$ and $\mathrm{m}$ is the mass of juice in grams.

The absorption coefficient $\left(\alpha_{254 \mathrm{~nm}}, \mathrm{~cm}^{-1}\right)$ of juice samples was determined by measuring absorbance at $254 \mathrm{~nm}$ in quartz cuvettes with path lengths of $0.05,0.10$, and $0.20 \mathrm{~mm}$ in a UV/Vis spectrophotometer (Ultraspec 3100 Pro, Biochrom Ltd., Cambridge, UK). The slope of the line taken from the plot of absorbance against path length was used to determine the absorption coefficient. 


\subsubsection{Colour}

A HunterLab LabScan XE spectrocolorimeter (Hunter Associates Laboratory, Inc., Reston, VA, USA) was used to measure the colour of juice samples in the CIELAB scale with the EasyMatchQC software. Samples were placed in a glass cup containing a black rubber ring on the inner walls $(54 \times 13 \mathrm{~mm})$ and covered with a white ceramic disk. The cup was then placed on a fitted sample plate and covered with a black sample cover prior to measuring. Samples were measured in triplicates and results was expressed as values of $L^{*}, a^{*}, b^{*}$, and $\Delta E$ for darkness/brightness, redness/greenness, yellowness/blueness, and total colour difference, respectively. A colour difference scale based on $\Delta \mathrm{E}$ values (not noticeable $=0$ to 0.5 , slightly noticeable $=0.5$ to 1.5 , noticeable $=1.5$ to 3.0, well noticeable $=3.0$ to 6.0 , greatly noticeable $=6.0$ to 12.0) was adapted from Koutchma et al. (2016) [4] .

\subsection{Nutritional Parameters}

\subsubsection{Protein Content}

A standard Lowry protein assay was used to determine the protein content in samples [6]. The absorbance was read in a UV/Vis spectrophotometer at $750 \mathrm{~nm}$. Results are expressed as $\mathrm{mg}$ BSA per $100 \mathrm{~mL}$.

\subsubsection{Total Phenolic Content}

Total phenolic content (TPC) was determined using the Folin-Ciocalteu assay as described by Zhang et al. (2015) with minor modifications [7]. Juice samples were initially filtered through a $0.45 \mu \mathrm{m}$ filter and diluted 10-fold. A gallic acid standard curve was generated using solutions between $15.625-500 \mu \mathrm{g} \mathrm{mL}^{-1}$. The absorbance at $765 \mathrm{~nm}$ was read using a 96 -well microplate reader (PowerWave XS2, BioTek Instruments Inc., Winooski, VT, USA). Results are expressed as mg gallic acid equivalent (GAE) per $\mathrm{L}$ of sample.

\subsubsection{Vitamin C Content}

Measurement of vitamin C content was carried out using the modified AOAC Titrimetric method (967.21) [8]. Approximately $5 \mathrm{~mL}$ of juice was diluted to $250 \mathrm{~mL}$ with distilled water, filtered through Whatman \#4 filter paper, and filtered again through $0.45 \mu \mathrm{m}$ Millipore filter paper before the addition of $0.2 \mathrm{~g}$ oxalic acid. The solution of juice was titrated using DPIP:distilled water (1:8). The titration was standardized with an ascorbic acid solution $\left(1 \mathrm{mg} \mathrm{mL}^{-1}\right)$ containing $0.2 \mathrm{~g}$ oxalic acid. The endpoint was recorded upon the first permanent appearance of a faint pink colour. Results are expressed as $\mathrm{mg}$ ascorbic acid per $100 \mathrm{~mL}$ of juice. Validation of this method was performed on a commercially available orange juice, and the results produced an estimate close to the value reported on the label.

\subsubsection{Oxygen Radical Absorbance Capacity}

The oxygen radical absorbance capacity (ORAC) of the GJB was determined according to procedures described by Zhang et al. (2015) [7]. Juice samples were filtered through a $0.45 \mu \mathrm{m}$ filter prior to the assay. The fluorescence was measured in a 96-well microplate reader (FLX800TBI, BioTek Instruments Inc., Winooski, VT, USA), with excitation and emission measured at $485 \mathrm{~nm}$ and $528 \mathrm{~nm}$, respectively. Results were expressed as $\mu \mathrm{M}$ Trolox equivalent (TE) per $\mathrm{mL}$ of juice.

\subsubsection{Free Radical Scavenging Capacity}

The free radical scavenging capacity (DPPH) of the GJB samples was determined according to the procedure described by Zhang et al. (2015) [7]. Samples were filtered through a $0.45 \mu \mathrm{m}$ filter prior to the assay. The absorbance of samples was measured at $517 \mathrm{~nm}$ in a 96-well microplate reader. Results were expressed as $\mathrm{mM} \mathrm{TE}$ per $\mathrm{mL}$ of juice. 


\subsection{Enzyme Activity}

\subsubsection{Polyphenoloxidase and Peroxidase}

Polyphenoloxidase (PPO) and peroxidase (POD) activities in the GJB were determined using a modified method developed by Bermejo-Prada and Otero (2016) [9]. In both assays, enzyme extraction was carried out by combining $3 \mathrm{~mL}$ of freshly thawed juice with $3 \mathrm{~mL}$ of an extraction buffer consisting of $0.2 \mathrm{M}$ sodium phosphate buffer $(\mathrm{pH}$ 6.5), $1 \mathrm{M}$ sodium chloride, $1 \%(w / v)$ polyvinylpolypirrolidone (PVPP), and 1\% $(v / v)$ Triton X-100. The mixture was centrifuged at $3200 \times g$ (Sorvall ST16R Centrifuge, Thermo Scientific, Waltham, MA, USA) at room temperature for $10 \mathrm{~min}$ and the supernatant was collected.

For the PPO assay, the substrate solution consisted of catechol $(0.07 \mathrm{M})$ prepared in extraction buffer which was filtered through a $0.45 \mu \mathrm{m}$ filter to remove any suspended PVPP. The reaction was initiated by adding $1 \mathrm{~mL}$ of 10 -fold diluted juice extract to $2 \mathrm{~mL}$ of substrate solution in a $1 \mathrm{~cm}$ disposable cuvette. The absorbance was measured using a UV-Vis spectrophotometer at $420 \mathrm{~nm}$ every $2 \mathrm{~s}$ for $10 \mathrm{~min}$ against a blank containing the filtered substrate solution.

For POD, a substrate solution containing $0.1 \%(w / v) p$-phenylenediamine in extraction buffer was filtered through a $0.45 \mu \mathrm{m}$ filter. Juice extracts $(300 \mu \mathrm{L})$ were diluted 5 -fold using distilled water to a final volume of $1.5 \mathrm{~mL}$ and combined with $25 \mu \mathrm{L}$ of diluted substrate solution and $725 \mu \mathrm{L}$ of filtered extraction buffer. The reaction was initiated by adding $50 \mu \mathrm{L}$ of $1.5 \%(v / v)$ hydrogen peroxide in a $1 \mathrm{~cm}$ disposable cuvette immediately before measuring the absorbance at $485 \mathrm{~nm}$ every $2 \mathrm{~s}$ for $20 \mathrm{~min}$. Blanks consisted solely of juice in extraction buffer.

PPO and POD activities were calculated from the slope of the linear portion of the respective plots of absorbance against time. Enzyme activity was expressed as enzyme units (U) per $\mathrm{mL}$ of juice $\left(\mathrm{U} \mathrm{mL}^{-1}\right)$, where one enzyme unit represents a change in absorbance of 0.01 per min.

\subsubsection{Pectin Methylesterase}

Pectin methylesterase (PME) activity was measured based on the method described by Hagerman and Austin (1986) with some modifications [10]. Juice extracts were prepared by centrifuging $35 \mathrm{~mL}$ of sample at $4700 \times g$ for $10 \mathrm{~min}$ and adjusting the $\mathrm{pH}$ to 7.5 . The substrate solution consisted of $1 \%(w / v)$ pectin and $0.3 \mathrm{M} \mathrm{NaCl}$. The assay was performed by mixing $500 \mu \mathrm{L}$ of $0.01 \%(w / v)$ bromothymol blue in extraction solution, $1 \mathrm{~mL}$ of the substrate solution, and $775 \mu \mathrm{L}$ of distilled water in a $1 \mathrm{~cm}$ disposable cuvette, followed by $250 \mu \mathrm{L}$ of juice extract to initiate the reaction. The sample was read at $620 \mathrm{~nm}$ every $2 \mathrm{~s}$ for $10 \mathrm{~min}$. Enzyme activity was expressed in the same manner as described for PPO and POD.

\subsection{Effects of Pressing Temperature and $p H$ on Cloud Loss and Browning of Kale and Romaine Juice}

Kale and romaine juices were pressed at $4{ }^{\circ} \mathrm{C}$ and $22{ }^{\circ} \mathrm{C}$ using the benchtop hydraulic press (Goodnature Countertop CT7; Orchard Park, NY, USA) and qualitative differences in sedimentation and browning were visually assessed after 4 days of storage at $4{ }^{\circ} \mathrm{C}$. Juice aliquots $(10 \mathrm{~mL})$ at $\mathrm{pH} 3.5$, $4.5,5.5$, and at natural $\mathrm{pH}($ Kale $=6.4$; Romaine $=6.3)$ were placed in $10 \mathrm{~mL}$ disposable vials. The $\mathrm{pH}$ of juice aliquots was adjusted with solutions of $1 \mathrm{M}$ and $6 \mathrm{M} \mathrm{HCl}$. Relative sediment height was determined on day $1,2,3$ and 4 by carefully measuring the ratio of sediment height to total sample height in the disposable vial $\left(H_{\text {sediment }} / H_{\text {total }} \%\right)$.

\subsection{Sensory Evaluation}

Differences between UV-C treated and untreated GJB samples were evaluated by a nine-member panel in a triangle test. Since only one sensory dimension and one factor (UV-C processing) differed between samples, it was possible to use a reduced number of panellists. Panellists were served three samples, with one being different from two duplicates, and asked to identify the different sample. Correct and incorrect responses were tallied and statistical significance was evaluated according to a 
critical number $(6)$ of correct responses $(\alpha=0.05)$, i.e., at least 6 members of the panel should correctly identify the different sample to establish statistical significance to a level of 0.05 [11].

\subsection{Statistical Analysis}

All experiments were repeated a minimum of three times except for total soluble solids, $\mathrm{pH}$, and absorption coefficient, for which a single sample was used to obtain three measurements. The statistical significance among tested groups was compared using the one-way ANOVA test for heterogeneity. The individual differences were assessed using a Tukey test if the ANOVA was significant. Statistical significance was determined at $p<0.05$. For microbiological data, a two-tailed $t$-test was used to evaluate statistical differences between the control and 100\% UV-C treatment at $p<0.05$. Microsoft Excel was used to perform all statistical analyses.

\section{Results and Discussion}

\subsection{Efftect of UV-C Light on Natural Microbiota}

Microbiological tests were conducted to determine the effect of UV-C exposure at $30 \%$ and $100 \%$ levels on the natural microbiota that affect the storage stability of the GJB. Tests for evaluating compliance with HACCP requirements with regards to pathogenic organisms were not conducted at this stage. Microbiological results for aciduric total count, aerobic colony count, lactic acid bacteria, coliforms, yeasts, moulds, and E. coli after exposure of the GJB to UV-C are shown in Table 4. At 30\% UV-C energy, the SLRs in aciduric count, aerobic count, yeasts, and moulds were 3, 4, 3, and 2 logs respectively. The treatment at $100 \% \mathrm{UV}-\mathrm{C}$ exposure resulted in similar reductions in aciduric and aerobic total counts of 3.7 and 3.9 logs, respectively. Specific logarithmic reductions of approximately 2.1 logs were observed for both moulds and yeasts following the $100 \%$ treatment. E. coli, lactic acid bacteria, and coliforms were not detected in any of the GJB UV-C treated samples. UV-C treatments ranging from $0.2-3.6 \mathrm{~kJ} \mathrm{~L}^{-1}$ have led to 1.0-3.0 log reductions in these microorganisms in fruit juices. However, the effectiveness of the treatment varies due to factors such as juice clarity, energy/fluence, and design of the UV-C unit [4]. Commercial units such as the SurePure UV-C reactor have achieved $\log$ reductions of 2-7 for yeasts in treated grape juice and wines [12].

Table 4. $\log _{10}$ (CFU/g) and specific logarithmic reductions (SLR) of aciduric total count, aerobic colony count, lactic acid bacteria, coliforms, yeasts, moulds, and E. coli, of untreated and treated GJB at 30\% and $100 \%$ UV-C energy with a commercial UV-C unit.

\begin{tabular}{|c|c|c|c|c|c|c|}
\hline \multirow{2}{*}{ Parameter } & \multicolumn{3}{|c|}{$30 \%\left(0.88 \mathrm{~kJ} \mathrm{~L}^{-1}\right)$} & \multicolumn{3}{|c|}{$100 \%\left(2.93 \mathrm{~kJ} \mathrm{~L}^{-1}\right)$} \\
\hline & $\begin{array}{c}\log _{10} \\
\text { (CFU/g) Untreated }\end{array}$ & $\begin{array}{c}\log _{10} \\
\text { (CFU/g) Treated }\end{array}$ & SLR & $\begin{array}{c}\log _{10} \\
(\mathrm{CFU} / \mathrm{g}) \text { Untreated }\end{array}$ & $\begin{array}{c}\log _{10} \\
\text { (CFU/g) Treated }\end{array}$ & SLR \\
\hline Aerobic total count & $7 \pm 0^{\mathrm{A}}$ & $3 \pm 0^{\mathrm{B}}$ & $4 \pm 0$ & $6.8 \pm 0.2^{\mathrm{a}}$ & $2.88 \pm 0.04^{b}$ & $3.9 \pm 0.2$ \\
\hline Lactic acid bacteria & $5 \pm 0$ & ND & $>3$ & $4.6 \pm 0.04$ & ND & $>3$ \\
\hline Coliforms & $3 \pm 0$ & ND & $>1$ & $3.4 \pm 0.05$ & ND & $>2$ \\
\hline E. coli ${ }^{*}$ & ND & ND & ND & ND & ND & ND \\
\hline
\end{tabular}

* Not detected (ND) Different superscript uppercase (A-B) or lowercase (a-b) letters in the same row indicate a significant difference between means $(p<0.05)$.

\subsection{Effect of UV-C Light on Physio-Chemical and Quality Parameters}

The physical and quality parameters of untreated and treated GJB are shown in Table 5. There was little to no change in the measured parameters as a result of both UV-C treatments. Identical values for total soluble solids, $\mathrm{pH}$, and titratable acidity were found for the untreated and treated GJB. No significant change $(p>0.05)$ in viscosity was detected in the treated samples. Previous reports have also shown that UV-C treatment did not affect $\mathrm{pH}$, total soluble solids, titratable acidity, or viscosity 
of fruit juices such as apple, orange and pomegranate [13-16]. No significant change in absorption coefficient of juice was observed in post UV-C treated samples.

Table 5. Physical and quality parameters of UV-C treated and untreated GJB using a commercial UV-C unit at $30 \%$ and $100 \%$ UV-C energy.

\begin{tabular}{|c|c|c|c|}
\hline Quality Parameters & Untreated & $\begin{array}{c}30 \% \\
\left(0.88 \mathrm{~kJ} \mathrm{~L}^{-1}\right) \\
\end{array}$ & $\begin{array}{c}100 \% \\
\left(2.93 \mathrm{~kJ} \mathrm{~L}^{-1}\right)\end{array}$ \\
\hline Total soluble solids (\%) & $6.8 \pm 0.7^{\mathrm{a}}$ & $6.8 \pm 0.7^{\mathrm{a}}$ & $6.8 \pm 0.7^{\mathrm{a}}$ \\
\hline $\mathrm{pH}$ & $3.39 \pm 0.3^{a}$ & $3.39 \pm 0.3^{a}$ & $3.39 \pm 0.3^{\mathrm{a}}$ \\
\hline Viscosity $(\mathrm{mPa} \cdot \mathrm{s})$ & $1.6 \pm 0.1^{\mathrm{a}}$ & $1.8 \pm 0.1^{\mathrm{a}}$ & $1.82 \pm 0.06^{\mathrm{a}}$ \\
\hline Titratable acidity $(\%)$ & $0.50 \pm 0.00^{\mathrm{a}}$ & $0.49 \pm 0.00^{a}$ & $0.50 \pm 0.00^{\mathrm{a}}$ \\
\hline Absorption coefficient, $\alpha_{254 \mathrm{~nm}}\left(\mathrm{~cm}^{-1}\right)$ & $22 \pm 2^{\mathrm{a}}$ & - & $24 \pm 2^{\mathrm{a}}$ \\
\hline$L^{*}$ & $33.7 \pm 0.2$ & $32.91 \pm 0.03$ & $33.01 \pm 0.07$ \\
\hline$a^{*}$ & $0.7 \pm 0.1$ & $-0.80 \pm 0.03$ & $0.01 \pm 0.004$ \\
\hline$b^{*}$ & $29.0 \pm 0.4$ & $27.70 \pm 0.07$ & $27.20 \pm 0.08$ \\
\hline$\Delta E$ & - & $-1.5 \pm 0.4$ & $-1.7 \pm 0.3$ \\
\hline
\end{tabular}

$\Delta E$ values represent the net change compared to a fresh untreated sample; colour difference scale based on $\Delta E$ (not noticeable $=0$ to 0.5 , slightly noticeable $=0.5$ to 1.5 , noticeable $=1.5$ to 3.0 , well noticeable $=3.0$ to 6.0 , greatly noticeable $=6.0$ to 12.0 ); total soluble solids $(\%), \mathrm{pH}$, and $\alpha_{254 \mathrm{~nm}}$ values were obtained from a single trial. Different superscript letters in the same row indicate a significant difference between means $(p<0.05)$.

UV-C treatment had a "slightly noticeable" $(0.5<\Delta E<1.5)$ net effect on colour in the sample treated at 30\% UV-C energy, and a "noticeable" $(1.5<\Delta E<3.0)$ effect on the sample treated at $100 \%$. For the $30 \%$ sample, the change in $L^{*}$ was "not noticeable" $(\Delta L=-0.49)$, whereas $a^{*}$ and $b^{*}$ were both "slightly noticeable" $(\Delta a=-1.5 ; \Delta b=-1.3)$. The $100 \%$ sample experienced changes to $L^{*}$ and $a^{*}$ that were both "slightly noticeable" $(\Delta a=-0.69)$, and a "noticeable" change in $b^{*}(\Delta b=-1.8)$. However, there was no clear difference between the treated and untreated juice samples that could be detected by eye. Previous studies have shown UV-C to have an insignificant effect on the colour parameters of fruit juices [4]. Watermelon, orange, and apple juices treated with UV-C energies up to $100 \mathrm{~kJ} \mathrm{~L}^{-1}$ retained their colour attributes and, in some cases, better preserved their colour during storage than untreated juices [4].

\subsection{Effect of UV-C Light on Nutritional Parameters}

The nutritional parameters of the untreated and treated GJB are displayed in Table 6. All parameters were unchanged by UV-C treatment at both UV-C energy levels. No significant reduction $(p>0.05)$ in protein content, TPC, or antioxidants activity (ORAC and DPPH) was found for the treated GJB. Koutchma et al. (2016) found no considerable change in the phenolic content of different fruit juices treated with a range of UV-C energies from 4.6-62.4 $\mathrm{kJ} \mathrm{L}^{-1}$ [4]. Insignificant $(p>0.05)$ changes in antioxidant capacity have also been reported for UV-C treated juices such as orange, pomegranate, grape, tomato, and starfruit $[4,17,18]$. To our knowledge, changes in protein content in juices treated with UV-C has not been previously studied. Vitamin C was not detected in either the untreated or treated samples.

Table 6. Nutritional parameters of UV-C treated and untreated GJB using a commercial UV-C unit at $30 \%$ and $100 \%$ UV-C energy.

\begin{tabular}{|c|c|c|c|}
\hline Nutritional Parameters & Untreated & $\begin{array}{c}30 \% \\
\left(0.88 \mathrm{~kJ} \mathrm{~L}^{-1}\right)\end{array}$ & $\begin{array}{c}100 \% \\
\left(2.93 \mathrm{~kJ} \mathrm{~L}^{-1}\right)\end{array}$ \\
\hline Protein $(\mathrm{mg} / 100 \mathrm{~mL})$ & $254 \pm 8^{a}$ & $255 \pm 25^{\mathrm{a}}$ & $251 \pm 17^{\mathrm{a}}$ \\
\hline Total phenolic content (mg GAE/L) & $224 \pm 3^{a}$ & $220 \pm 10^{a}$ & $223 \pm 13^{a}$ \\
\hline Vitamin C $(\mathrm{mg} / 100 \mathrm{~mL})$ & 0 & - & 0 * \\
\hline ORAC (mM TE/mL) & $3.7 \pm 0.5^{\mathrm{a}}$ & $3.8 \pm 0.5^{\mathrm{a}}$ & $3.6 \pm 0.5^{\mathrm{a}}$ \\
\hline $\mathrm{DPPH}(\mathrm{mM} \mathrm{TE} / \mathrm{mL})$ & $0.93 \pm 0.07^{\mathrm{a}}$ & $0.88 \pm 0.07^{\mathrm{a}}$ & $0.87 \pm 0.07^{\mathrm{a}}$ \\
\hline
\end{tabular}

* Only the GJB treated at 100\% UV-C energy was tested. Different superscript letters in the same row indicate a significant difference between means $(p<0.05)$. 


\subsection{Enzymes}

\subsubsection{PPO, POD, and PME Activities in the GJB}

Activities of PPO, POD, and PME in the GJB were assessed following treatment with the commercial UV-C unit at 30\% and 100\% energy (Table 7). With the exception of a slight increase $(p<0.05)$ in PPO activity following the $30 \%$ treatment, no other statistically significant $(p>0.05)$ changes in enzyme activity were observed. To our knowledge, this is the first report of the effect of UV-C light on enzyme activity in green juice. Koutchma et al. (2016) have shown that enzyme activity in fruit juice from various studies was dependent on UV-C energy, emission wavelength of the lamp, and juice composition. Significant reductions in enzyme activity primarily occurred when using high UV-C energies, medium pressure polychromatic lamps, or in high UVT liquids such as buffers. The UV-C energy used in this study at 30\% and $100 \%$ treatment levels $\left(0.88\right.$ and $\left.2.93 \mathrm{~kJ} \mathrm{~L}^{-1}\right)$ was relatively low when compared with previously reported values in continuous systems. With the exception of one study in apple juice $\left(1.5 \mathrm{~kJ} \mathrm{~L}^{-1}\right)$, all other enzyme activities were reported using UV-C energies between 4.8-108 $\mathrm{kJ} \mathrm{L}^{-1}$. An enhancement in residual enzyme activity was only reported for PPO (114.5\%) using a UV-C energy of $1.5 \mathrm{~kJ} \mathrm{~L}^{-1}$ [19]. We also observed a slight enhancement in PPO activity using similar UV-C energy values, though only the result for the treatment at $30 \%$ energy was significant. These results seem to indicate that PPO activity could be enhanced during low UV-C energy treatments.

Table 7. The effect of UV-C treatment on PPO, POD, and PME activities in the GJB using a commercial UV-C unit at $30 \%$ and $100 \%$ energy.

\begin{tabular}{|c|c|c|c|}
\hline \multirow{2}{*}{ Enzyme } & \multicolumn{3}{|c|}{ Activity ( $\mathrm{U} \mathrm{mL}^{-1}$ of Juice) } \\
\hline & Untreated & $30 \%\left(0.88 \mathrm{~kJ} \mathrm{~L}^{-1}\right)$ & $100 \%\left(2.93 \mathrm{~kJ} \mathrm{~L}^{-1}\right)$ \\
\hline $\mathrm{PPO}$ & $59 \pm 5^{\mathrm{a}}$ & $66 \pm 3^{b}$ & $63 \pm 3^{a, b}$ \\
\hline POD & $48 \pm 5^{\mathrm{a}}$ & $47 \pm 4^{\mathrm{a}}$ & $46 \pm 5^{\mathrm{a}}$ \\
\hline PME & $1.03 \pm 0.06^{\mathrm{a}}$ & $0.92 \pm 0.05^{\mathrm{a}}$ & $0.95 \pm 0.02^{\mathrm{a}}$ \\
\hline
\end{tabular}

Different superscript letters in the same row indicate a significant difference between means $(p<0.05)$.

\subsubsection{PPO, POD, and PME Activities of Individual Components in the GJB}

In order to identify the primary source of PPO, POD, and PME activities in the GJB, individual juice components were pressed and assayed separately. We observed that kale juice was the primary source of PME and POD enzymes in the GJB while romaine juice was the primary source of PPO enzyme. Lemon juice was also shown to contribute to PME activity to a lesser extent (Figure 2). Given that UV-C treatment has not been shown to inactivate PPO, POD, and PME, it is important to investigate the effect these enzymes will have on the suspension stability and quality of UV-C processed juices rich in kale and romaine.

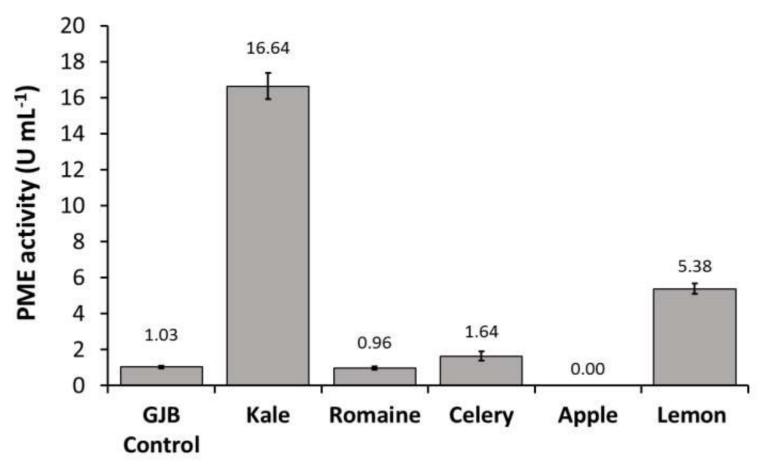

Figure 2. Cont. 


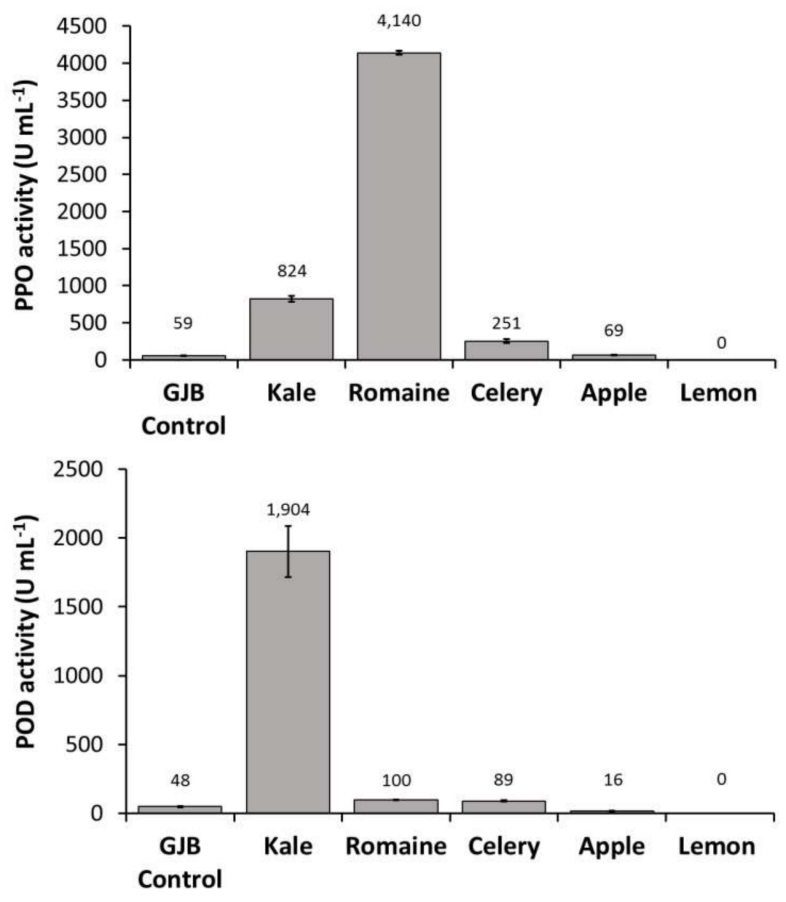

Figure 2. PPO, POD, and PME activities of the GJB in comparison to its individual components (kale, romaine, celery, apple, and lemon) when separately cold-pressed and assayed.

\subsubsection{Effect of Pressing Temperature on PPO, POD, and PME Activity in Kale and Romaine Juice}

The effect of pressing temperature on PME and POD activity from kale juice and PPO activity from romaine juice is shown in Figure 3. A non-significant $(p>0.05)$ change in the activity of each enzyme was observed when the juices were pressed at room temperature versus at $4{ }^{\circ} \mathrm{C}$. These results indicate that pressing temperature has a negligible effect on tested enzyme activities.
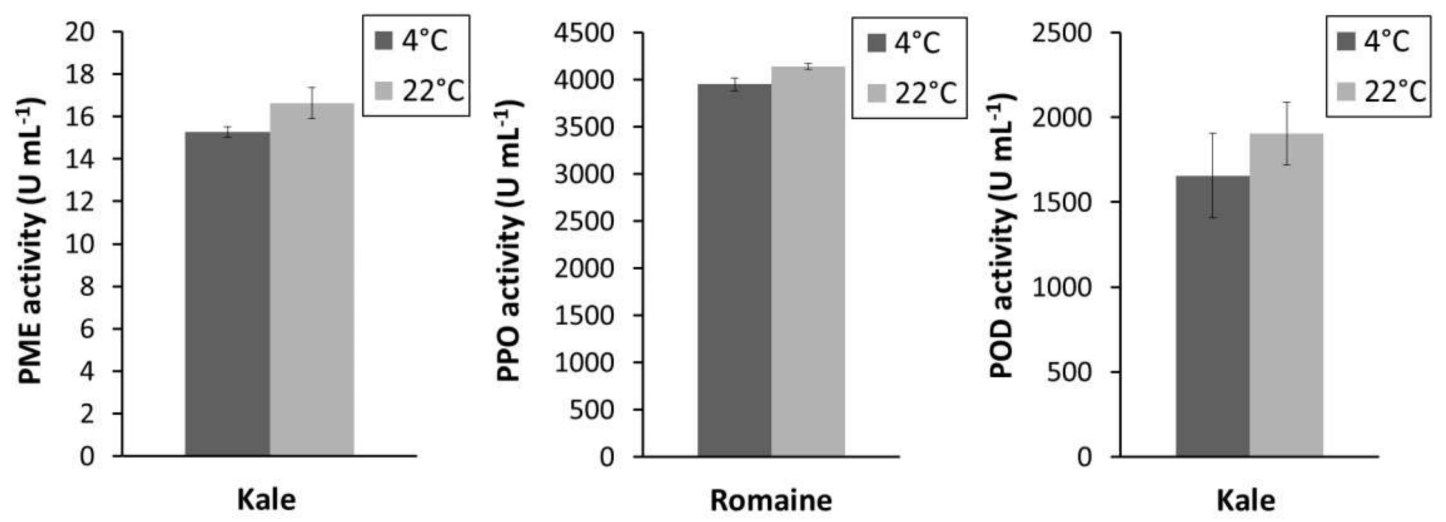

Figure 3. PPO, POD, and PME activities in kale and romaine juice when pressed at $4{ }^{\circ} \mathrm{C}$ or $22^{\circ} \mathrm{C}$.

3.4.4. Effects of Pressing Temperature and $\mathrm{pH}$ on Cloud Loss and Browning of Kale and Romaine Juice

A visual comparison of the suspension stability and browning of kale and romaine juices pressed at $4{ }^{\circ} \mathrm{C}$ and $22{ }^{\circ} \mathrm{C}$ following a four-day storage period at $4{ }^{\circ} \mathrm{C}$ is shown in Figure 4. Pressing temperature appears to have the most significant effect on cloud loss and browning in kale juice, which exhibits a greater degree of sedimentation and browning compared to when it is pressed at $4{ }^{\circ} \mathrm{C}$. Unlike kale, there is no obvious difference in sedimentation between the romaine juices pressed at $4{ }^{\circ} \mathrm{C}$ and $22{ }^{\circ} \mathrm{C}$. Pressing romaine juice at $22{ }^{\circ} \mathrm{C}$ instead of $4{ }^{\circ} \mathrm{C}$ appears to result in more browning. 


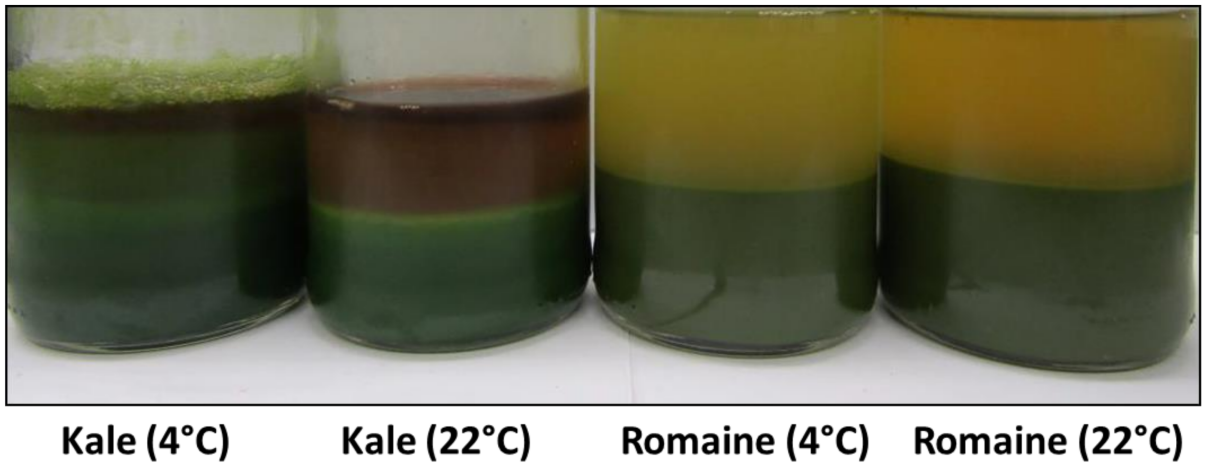

Figure 4. Kale and romaine juices pressed at $4{ }^{\circ} \mathrm{C}$ and $22^{\circ} \mathrm{C}$ after four days.

The relative sedimentation height and browning of kale and romaine juices adjusted to different $\mathrm{pH}$ levels and stored at $4{ }^{\circ} \mathrm{C}$ for four days are shown in Figure 5. The change in relative sediment height of both juices are given in Table 8 . Decreases in sediment height were likely the result of tighter packing of non-suspended juice particles. There was no measured change in the height of the layer for the romaine samples at natural $\mathrm{pH}$ and $\mathrm{pH}$ 5.5.

The rate of sedimentation and packing appeared to increase with decreasing $\mathrm{pH}$. On the fourth day, a second layer composed of finer particulates was observed in the kale sample at $\mathrm{pH}$ 6.4. This layer appeared to fall out of suspension and pack more quickly as $\mathrm{pH}$ was lowered. It is unclear why the relative sediment height of the kale sample at $\mathrm{pH} 4.5$ was higher than at $\mathrm{pH} 5.5$ and 4.5 . In both juices, less browning was observed at lower $\mathrm{pH}$ levels; an effect most noticeable at $\mathrm{pH} 3.5$. This was expected since browning enzymes PPO and POD are less active at lower pH levels [20]. Kale juice appeared to experience more browning than romaine juice. It was observed that juice cloud stability is directly influenced by $\mathrm{pH}$. The observed trend cannot be explained solely by PME activity, since sedimentation occurred more slowly in the less acidic juices where PME was expected to be most active [21]. This same trend has been observed to varying degrees depending on juice batches (data not shown). Future studies should seek to better understand the effects of $\mathrm{pH}$ on green juice stability to minimize the effects of browning and sedimentation.

Day 0

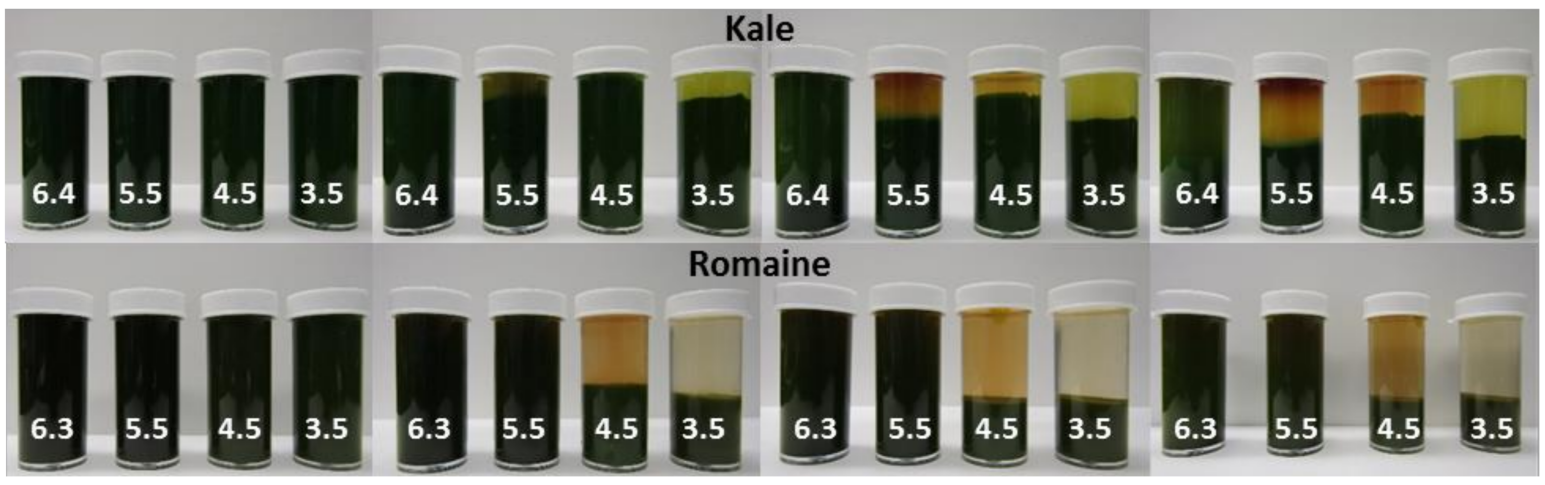

Figure 5. Kale (top) and romaine (bottom) juices at varying $\mathrm{pH}$ levels stored at $4{ }^{\circ} \mathrm{C}$ for four days. 
Table 8. Relative sediment height $\left(H_{\text {sediment }} / H_{\text {total }} \%\right)$ of kale and romaine juice samples at natural $\mathrm{pH}$, $\mathrm{pH} 5.5,4.5$, and 3.5 while stored at $4{ }^{\circ} \mathrm{C}$ over four days.

\begin{tabular}{|c|c|c|c|c|c|c|c|c|}
\hline \multirow{3}{*}{$\begin{array}{c}\text { Days } \\
\text { Elapsed }\end{array}$} & \multicolumn{8}{|c|}{$H_{\text {sediment }} / H_{\text {total }}(\%)$} \\
\hline & \multicolumn{4}{|c|}{ Kale } & \multicolumn{4}{|c|}{ Romaine } \\
\hline & pH 6.4 & pH 5.5 & pH 4.5 & pH 3.5 & pH 6.3 & pH 5.5 & pH 4.5 & pH 3.5 \\
\hline 1 & $22 \pm 1^{A}$ & $70.1 \pm 0.1^{\mathrm{B}}$ & $94 \pm 6^{C}$ & $72 \pm 2^{B}$ & $100.0 \pm 0.0^{a}$ & $100.0 \pm 0.0^{a}$ & $48.3 \pm 0.7^{b}$ & $40.4 \pm 0.0^{\mathrm{c}}$ \\
\hline 2 & $24 \pm 1^{\mathrm{A}}$ & $61.4 \pm 0.2^{B}$ & $80 \pm 3^{C}$ & $61.1 \pm 0.4^{\mathrm{B}}$ & $100.0 \pm 0.0^{\mathrm{a}}$ & $100.0 \pm 0.0^{\mathrm{a}}$ & $34.0 \pm 0.0^{b}$ & $34.0 \pm 0.0^{b}$ \\
\hline 3 & $21.7 \pm 0.8^{\mathrm{A}}$ & $57.5 \pm 0.8^{B}$ & $73 \pm 3^{C}$ & $56.4 \pm 0.3^{B}$ & $100.0 \pm 0.0^{\mathrm{a}}$ & $100.0 \pm 0.0^{\mathrm{a}}$ & $32.8 \pm 0.3^{b}$ & $33.8 \pm 0.4^{b}$ \\
\hline 4 & $42.1 \pm 0.6^{\mathrm{A}}$ & $50.8 \pm 0.2^{B}$ & $69.3 \pm 0.4^{C}$ & $52.9 \pm 0.3^{B}$ & $100.0 \pm 0.0^{\mathrm{a}}$ & $100.0 \pm 0.0^{a}$ & $32.1 \pm 0.3^{b}$ & $32.8 \pm 0.3^{b}$ \\
\hline
\end{tabular}

Different superscript uppercase $(\mathrm{A}-\mathrm{C})$ or lowercase $(\mathrm{a}-\mathrm{c})$ letters in the same row indicate a significant difference between means $(p<0.05)$.

\subsection{Sensory Changes}

A triangle test was used to determine whether there is a noticeable difference in overall sensory qualities between two control juice samples and one treated juice sample. A nine-member panel evaluated the differences between untreated GJB and GJB treated at 30\% UV-C energy, and between untreated GJB and GJB treated at 100\% UV-C energy. In both cases, the panellists gave four correct and five incorrect responses. These results indicate that there is no significant difference $(p>0.05)$ between the treated and untreated GJB.

\section{Conclusions}

UV-C treatment of a cold-pressed GJB using an industrial-scale UV-C processing unit at energies of $0.88 \mathrm{~kJ} \mathrm{~L}^{-1}$ and $2.93 \mathrm{~kJ} \mathrm{~L}^{-1}$ led to a reduction in natural microbiota, yeasts and moulds without significantly altering physical, quality, nutritional and sensory parameters. A minor increase in PPO enzyme activity was seen with $0.88 \mathrm{~kJ} \mathrm{~L}^{-1}$, and an imperceptible change in colour was detected for the GJB treated at $2.93 \mathrm{~kJ} \mathrm{~L}^{-1}$. Otherwise, no statistically significant changes in enzymatic, nutritional, quality, or sensory parameters were observed for the GJB. Additional work is required to fully understand the reason for the observed enhancement of PPO activity. Kale juice was found to be the largest contributor of PME and POD enzyme activities, while romaine juice was primarily responsible for PPO enzyme activity in the GJB. The degree of cloud loss and browning of the kale and romaine juice was shown to be affected by pressing temperature and juice $\mathrm{pH}$.

The observed lack of spoilage enzyme inactivation may reduce the stability of the juice products using leafy green ingredients and therefore pose a challenge to product appearance during long-term storage. For this reason, juice stability should be taken into consideration in addition to spoilage organisms counts when attempting to extend shelf-life. To our knowledge, this is the first report of activity of spoilage enzymes of PME, PPO and POD in a juice incorporating leafy green produce as well as the effects of UV-C treatment on these enzymes. Future studies should examine the effect of altering treatment parameters on juice products stability to reduce cloud loss and browning. The lower initial investment, operating costs, packaging flexibility and size requirements associated with a UV-C treatment show the feasibility of this technology as the primary non-thermal processing alternative for the premium juice category.

Acknowledgments: We would like to thank AseptoRay (Ma'alot-Tarshiha, Israel) for allowing us to test their commercial UV-C unit and Goodnature (New York, NY, USA) for providing us with the countertop juice processor and cold press.

Author Contributions: Michael Biancaniello: Researched prior studies, conducted experiments, interpreted results, and drafted the manuscript. Vladimir Popović: Researched prior studies, assisted with experiments and interpreting results, and drafted the manuscript. Cristina Fernandez-Avila: Assisted with microbiological analysis of GJB and drafted sections of the manuscript. Valquiria Ros-Polski: Assisted with microbiological analysis of GJB and drafted sections of the manuscript. Tatiana Koutchma: Researched prior studies, analyzed and interpreted results, and drafted the manuscript.

Conflicts of Interest: The authors declare no conflict of interest. 


\section{References}

1. Hogan, E.; Kelly, A.L.; Sun, D.-W. High pressure processing of foods: An overview. In Emerging Technologies for Food Processing; Academic Press: London, UK, 2005; pp. 3-32.

2. Ultraviolet Light Treatment of Apple Juice/Cider Using the Cidersure 3500; Health Canada: Ottawa, ON, Canada, 2003.

3. Irradiation in the Production, Processing and Handling of Food. Final Rule; U.S. FDA: Silver Spring, MD, USA, 2001; Volume 77, pp. 71312-71316.

4. Koutchma, T.; Popović, V.; Ros-Polski, V.; Popielarz, A. Effects of ultraviolet light and high-pressure processing on quality and health-related constituents of fresh juice products. Compr. Rev. Food Sci. Food Saf. 2016, 15, 844-867. [CrossRef]

5. AOAC. Official Methods of Analysis, 16th ed.; AOAC International: Arlington, VA, USA, 1995.

6. Lowry, O.H.; Rosebrough, N.J.; Farr, A.L.; Randall, R.J. Protein measurement with the folin phenol reagent. J. Biol. Chem. 1951, 193, 265-275. [PubMed]

7. Zhang, B.; Deng, Z.; Ramdath, D.D.; Tang, Y.; Chen, P.X.; Liu, R.; Liu, Q.; Tsao, R. Phenolic profiles of 20 canadian lentil cultivars and their contribution to antioxidant activity and inhibitory effects on $\alpha$-glucosidase and pancreatic lipase. Food Chem. 2015, 172, 862-872. [CrossRef] [PubMed]

8. AOAC. Ascorbic acid in vitamin preparations and juices 2,6-dichloroindophenol titrimetric method. In Official Methods of Analysis; AOAC International: Arlington, VA, USA, 1995; pp. 16-17.

9. Bermejo-Prada, A.; Otero, L. Effect of hyperbaric storage at room temperature on color degradation of strawberry juice. J. Food Eng. 2016, 169, 141-148. [CrossRef]

10. Hagerman, A.E.; Austin, P.J. Continuous spectrophotometric assay for plant pectin methyl esterase. J. Agric. Food Chem. 1986, 34, 440-444. [CrossRef]

11. Roessler, E.B.; Pangborn, R.M.; Sidel, J.L.; Stone, H. Expanded statistical tables for estimating significance in paired-preference, paired-difference, duo-trio and triangle tests. J. Food Sci. 1978, 43, 940-943. [CrossRef]

12. Lorenzini, M.; Fracchetti, F.; Bolla, V.; Stefanelli, E.; Rossi, F.; Torriani, S. Ultraviolet light (uv-c) irradiation as an alternative technology for the control of microorganisms in grape juice and wine. In Proceedings of the 33rd World Congress of Vine and Wine, 8th General Assembly of the OIV, Tbilisi, Georgia, 20-25 June 2010.

13. Caminiti, I.M.; Palgan, I.; Muñoz, A.; Noci, F.; Whyte, P.; Morgan, D.J.; Cronin, D.A.; Lyng, J.G. The effect of ultraviolet light on microbial inactivation and quality attributes of apple juice. Food Bioprocess Technol. 2010, 5, 680-686. [CrossRef]

14. Pala, Ç.U.; Toklucu, A.K. Effect of uv-c light on anthocyanin content and other quality parameters of pomegranate juice. J. Food Compos. Anal. 2011, 24, 790-795. [CrossRef]

15. Pala, Ç.U.; Toklucu, A.K. Effects of uv-c light processing on some quality characteristics of grape juices. Food Bioprocess Technol. 2012, 6, 719-725. [CrossRef]

16. Zhang, C.; Trierweiler, B.; Li, W.; Butz, P.; Xu, Y.; Rüfer, C.E.; Ma, Y.; Zhao, X. Comparison of thermal, ultraviolet-c, and high pressure treatments on quality parameters of watermelon juice. Food Chem. 2011, 126, 254-260. [CrossRef]

17. Bhat, R. Impact of ultraviolet radiation treatments on the quality of freshly prepared tomato (solanum lycopersicum) juice. Food Chem. 2016, 213, 635-640. [CrossRef] [PubMed]

18. Bhat, R.; Ameran, S.B.; Voon, H.C.; Karim, A.A.; Tze, L.M. Quality attributes of starfruit (averrhoa carambola 1.) juice treated with ultraviolet radiation. Food Chem. 2011, 127, 641-644. [CrossRef] [PubMed]

19. Orlowska, M.; Koutchma, T.; Kostrzynska, M.; Tang, J.; Defelice, C. Evaluation of mixing flow conditions to inactivate escherichia coli in opaque liquids using pilot-scale taylor-couette uv unit. J. Food Eng. 2014, 120, 100-109. [CrossRef]

20. Mizobutsi, G.P.; Finger, F.L.; Ribeiro, R.A.; Puschmann, R.; Neves, L.L.D.M.; Mota, W.F.D. Effect of pH and temperature on peroxidase and polyphenoloxidase activities of litchi pericarp. Sci. Agric. 2010, 67, $213-217$. [CrossRef]

21. Unal, M.U.; Sener, A. Extraction and characterization of pectin methylesterase from alyanak apricot (prunus armeniaca 1). J. Food Sci. Technol. 2015, 52, 1194-1199. [CrossRef] [PubMed]

(C) 2018 by the authors. Licensee MDPI, Basel, Switzerland. This article is an open access article distributed under the terms and conditions of the Creative Commons Attribution (CC BY) license (http:/ / creativecommons.org/licenses/by/4.0/). 